Int. J. Dev. Biol. 62: 97-107 (2018)

https://doi.org/10.1387/ijdb.170321ja

\title{
Craniofacial development: discoveries made in the chicken embryo
}

\author{
JOHN ABRAMYAN*,1 and JOY M. RICHMAN*,2 \\ ${ }^{1}$ Department of Natural Sciences, University of Michigan-Dearborn, Dearborn, Michigan, USA and \\ ${ }^{2}$ Life Sciences Institute and Faculty of Dentistry, University of British Columbia, Vancouver, Canada
}

\begin{abstract}
The aim of this review is to highlight some of the key contributions to our understanding of craniofacial research from work carried out with the chicken and other avian embryos. From the very first observations of neural crest cell migration to the fusion of the primary palate, the chicken has proven indispensable in facilitating craniofacial research. In this review we will look back to the premolecular studies where "cut and paste" grafting experiments mapped the fate of cranial neural crest cells, the role of different tissue layers in patterning the face, and more recently the contribution of neural crest cells to jaw size and identity. In the late 80 's the focus shifted to the molecular underpinnings of facial development and, in addition to grafting experiments, various chemicals and growth factors were being applied to the face. The chicken is above all else an experimental model, inviting hands-on manipulations. We describe the elegant discoveries made by directly controlling signaling either in the brain, in the pharyngeal arches or in the face itself. We cover how sonic hedgehog (Shh) signals to the face and how various growth factors regulate facial prominence identity, growth and fusion. We also review abnormal craniofacial development and how several type of spontaneous chicken mutants shed new light on diseases affecting the primary cilium in humans. Finally, we bring out the very important role that the bird beak has played in understanding amniote evolution. The chicken, duck and quail have been and will continue to be used as experimental models to explore the evolution of jaw diversity and the morphological constraints of the vertebrate face.
\end{abstract}

KEY WORDS: craniofacial, facial prominence, morphogenesis, beak development, maxillary, mandibular, frontonasal

\section{Introduction}

In this review craniofacial development in the chicken embryo will be discussed. The focus will be on questions that can be best addressed by using an accessible animal like the avian embryo. Topics we will cover include the origins of facial tissues gleaned from cut-and-paste, interspecific experiments, the morphogenesis of the beak, the participation of specific signaling pathways in different aspects of facial patterning, models of abnormal beak development including spontaneous mutant chicken lines, and evo-devo studies involving the beaks of modern birds and nonavian reptiles. Throughout this review, the common theme is the high degree of conservation between chicken facial ontogeny and other model organisms. Thus the findings made in the chicken are relevant to our understanding of human development and disease.
Techniques to study craniofacial development in the chicken embryo

Before reviewing the craniofacial research that was carried out on the chicken embryo, it is important to provide some technical context. The main way in which the chicken shines as a model organism is that direct interventions are possible at early stages and can be followed until the full structure has been elaborated. However the craniofacial region presents unique challenges compared to other organs such as the neural tube and limb buds. One

\footnotetext{
Abbreviations used in this paper: BMP, bone morphogenetic protein; FGF, fibroblast growth factor; NCC, neural crest cell; RA, retinoic acid; RCAS virus, replicationcompetent ASLV long terminal repeat with a splice acceptor; $\mathrm{SHH}$, sonic hedgehog; WNT, wingless-type MMTV integration site.
} 
of the main issues is that the skull forms relatively late in chicken development (12-14 days). It requires skill to keep the embryo alive for 2 weeks following complex surgical procedures. Also, the heart develops very close to the face, thus lethality is a common complication. Furthermore, the avian embryo turns on its side at the pharyngula stage, making the centre of the face difficult to access. Nevertheless we and others have remained passionate about using the chicken embryo for craniofacial research.

The methods most commonly employed are cutting and pasting of tissues from one embryo to another, either in the same location or an ectopic location. The soaking of microscopic beads in compounds (agonists or antagonists) and then implanting them in the face is also a favorite method to change the levels of signaling with great temporal and spatial precision. Exogenous genes can also be delivered using electroporation or the Replication-Competent ASLV long terminal repeat with a Splice acceptor (RCAS) system (Gordon et al., 2009). Electroporation is very challenging to carry out in the face due to the proximity of the heart. However some labs have had success with this method (Hu et al., 2015). For more global expression changes in a region of the embryo, the RCAS retrovirus is the preferred method. The virus is avian-specific and permits local misexpression in regions of the face while allowing normal development in the rest of the embryo. Viruses may be utilized to introduce an exogenous gene (Abzhanov and Tabin, 2004, Eames et al., 2004, Foppiano et al., 2007, Hu et al., 2008), mutant versions of a gene (Hosseini-Farahabadi et al., 2017) or less commonly, to knock down a gene using an shRNA cassette (Bond et al., 2016). Moreover, since conservation of protein sequence is very high in developmental genes, the exogenous gene used for overexpression may be from the chicken or another species. The advantage of using sequence from another species is that the level of exogenous gene expression can be subsequently measured against the backdrop of endogenous target gene changes from the chicken. We have previously quantified the levels of expression from RCAS viruses (Geetha-Loganathan et al., 2014, Hosseini-Farahabadi et al., 2017, Nimmagadda et al., 2015) and measured gradual increases in expression between 48 and $96 \mathrm{~h}$. Interestingly, the overexpression of genes can be used to detect target genes and importantly, to exclude those that are not likely to be involved in a particular pathway. Thus we would argue that the virus overexpression experiments provide physiologically relevant information.

It is more difficult to carry out loss of function experiments in the face of the chicken embryo. Reagents such as antisense Morpholinos (MO) work well in some locations such as the neural tube (Norris and Streit, 2014), but not at all in the face. Other methods to interfere with gene function seem to be more effective. Electroporation of a mutant $\mathrm{SHH}$ (Sonic Hedghog) receptor Patched has been successfully carried out. This PTCALoop ${ }^{2}$ construct lacks a domain that prevents signal transduction in the presence of $\mathrm{SHH}$ ligand (Hu et al., 2015). Electroporation seems to work in targeting patches of ectoderm such as in the lip fusion zone but is less useful for targeting facial mesenchyme.

As an alternative to retroviruses, we have tested several types of lipid nanoparticles for nucleic acid delivery (Geetha-Loganathan et al., 2009, Kulkarni et al., 2017). These nanoparticles are capable of over expression or knockdown. Plasmids expressing an shRNA construct targeting gallus WNT11 led to decreased gene expression (Geetha-Loganathan et al., 2014) and rounding of the cells in which it was expressed. The lipid-based transfection method is not global, but is a great way to create a mixed population of labeled and unlabeled cells.

Although the learning curve is steep, the value of locally controlling gene and signaling pathway activity in the face or to use unbiased, grafting methods, offers the chance to address important research questions in highly creative ways that are not available in other amniote models.

\section{Cranial neural crest cells and their contribution to the head skeleton}

The chicken and quail were the first animals to be used for long-term lineage mapping of neural crest cells (Le Lievre, 1978, Noden, 1975, Noden, 1983). At the early stages of craniofacial patterning, functionally equivalent cranial neural crest cells derived from the prosencephalon, mesencephalon and rhombomeres 1,2 migrate into the ventral region of the head, filling the pharyngeal arches (Couly et al., 1996, Koentges and Lumsden, 1996) (Fig. $1 \mathrm{~A})$. These facial neural crest cells contribute to the skeleton supporting the upper and lower beaks, anterior calvaria (frontal bones) and anterior cranial base (Couly et al., 1993, Le Lievre, 1978, Noden, 1975). Non-skeletal neural crest cell derivatives include melanocytes, connective tissue, smooth muscle, fascia, as well as parts of the peripheral nervous system, just to name a few (Creuzet et al., 2005).

In addition to their interaction with specific germ layers, neural crest cells are patterned by the HOX code found along the anteroposterior axis of animals. The anterior neural tube segments (prosencephalon and mesencephalon) do not express members of the Antennapedia HOX gene clusters, whereas posterior regions of the neural tube do (Fig. 1A)(Couly et al., 1996). Consequently, when HOX-negative neural crest cell progenitors derived from anterior neural tube are transplanted into posterior regions, normal development of ectopic mandibular structures are produced (Noden, 1983). However, in an inverse experiment, when HOXA2 was artificially introduced into the anterior cranial neural crest via electroporation, jaw development was inhibited (Creuzet et al., 2002). Whether there are factors that actively repress HOXA2 or other HOX genes in the anterior neural crest is unknown.

Premigratory cranial neural crest cells contain important information controlling the size of skeletal elements. Grafts of quail neural crest cells into the duck embryo changed the size and shape of the beaks to be pointed and smaller; resembling the donor species, the quail (Eames and Schneider, 2008, Fish et al., 2014, Schneider and Helms, 2003, Tucker and Lumsden, 2004). Timing of development is also intrinsically controlled. The quail hatches in 17 days whereas the duck takes $\mathbf{2 8}$ days to hatch (Eames and Schneider, 2008). At the beginning of neural crest cell migration, there is a proportionately larger group of cells dorsal to the neural tube in the duck than in the quail (Fish et al., 2014). These early differences lead to more mesenchymal cells in the face and subsequently to larger skeletal elements in the duck. The quail-duck studies also revealed that intrinsic cell cycle times are retained in neural crestderived cells, even when interspecific grafts are made (Fish et al., 2014). Thus cranial neural crest cells are preprogrammed to contain main elements of the craniofacial pattern with some details to be specified later, such as the arrangements of bones and cartilages (Noden, 1983, Trainor et al., 2002). 


\section{The first pharyngeal arch contributions to the face}

The next stage of craniofacial development is the entry of neural crest cells into the ventrally positioned pharyngeal arches. The pharyngeal arches are repeated segments and each one contains similar elements (skeletal tissue, musculature, neurovascular bundle) (Fig. 1B) (Graham, 2003, Veitch et al., 1999). It has previously been shown that the segmental characteristics of the pharyngeal pouches develop independently of the presence of the neural crest cells (Veitch et al., 1999). This suggests that at least part of the information for patterning the face could originate from signals within the endoderm (Couly et al., 2002). Indeed a series of studies from the laboratory of Nicole Le Douarin showed that the foregut endoderm of the chicken embryo (which will later line the pharyngeal pouches, Fig. 1B) specifies identity and orientation of the neural crest-derived facial skeleton including mandible (Brito et al., 2006, Couly et al., 2002) and nasal capsule (Benouaiche et al., 2008).

The neural crest-derived mesenchyme within the first pharyngeal arch condenses to form a dorsal condensation (future maxillary prominence) below the eye, and a ventral condensation (future mandibular prominence) below the oral cavity; leaving a maxillo-mandibular cleft representing the "hinge" between the jaws (Depew and Compagnucci, 2008, Tak et al., 2017). The respective prominence condensations ultimately form the skeletal structures of the jaws: the Meckel's cartilage and dentary (embryonic skeleton of the lower jaw) and the palatine, jugal and maxillary bones (embryonic skeleton of the upper jaw) (Fig. 1B-D). However, some aspects of this hypothesis have been recently called into question.

Cerny and colleagues injected Dil into the presumptive "maxillary" and "mandibular" prominences of the first pharyngeal arch of stage 13-14 chicken embryos (Cerny et al., 2004). They found that a single condensation of cells, ventrally located in the first pharyngeal arch, gives rise to both maxillary and mandibular jaw cartilages, and which they refer to as 'maxillomandibular' region. On the other hand, the dorsal condensation of the first pharyngeal arch was found to give rise to the trabeculae cranii, which were thought to be anterior neurocranial structures (Cerny et al., 2004). However, a similar study performed by our laboratory found that

Fig. 1. Overview of craniofacial development in the chicken embryo. (A) Hox-negative neural crest cells (NCC, pink) move out from the primitive brain, through the paraxial mesoderm (black) and into ventral face (inset). Hox-positive neural crest cell streams originate from below r4 (NCC, blue). (B) On the left is an external view showing areas of face populated by NCC. On the right is a midsagittal slice, showing the position of neural crestderived mesenchyme (pink) and mesoderm in the pharyngeal arches and ventral to the brain. The pharynx is lined with endoderm (green). (C) Facial prominences are color coded to match their skeletal derivatives shown in panel D. (D) Sagittal and palatal views of the skull. In palatal view, upper half is the fate map, lower half is showing intramembranous bones. Below is an overview of the intramembranous and endochondral bones of the head. KEY: an - angular, ar-retroarticular process, de - dentary, fnm - frontonasal mass, ios - interorbital septum, j- jugal, Inp - lateral nasal prominence, $m$ - mesencephalon, mc-Meckel's cartilage, mdmandibular prominence, $m \times p$-maxillary prominence, $m x$ - maxillary bone, $n$-notochord, $n p$ - nasal pit, $p$-prosencephalon (in panel A), $p$-palatine (in panel D), pa - pharyngeal arch, pmx - premaxilla, pnc - prenasal cartilage, pt-pterygoid, q-quadrate, qj-quadratojugal, r-rhombencephalon, $r 1(-r 7)$ - rhombomeres 1-7, s-somite, san - surangular, sp - splenial. the injection of dye in the post-optic region labeled the center of the stomodeal roof where the trabecular cartilages will later form. Thus we have pinpointed the stage where midline mesenchyme
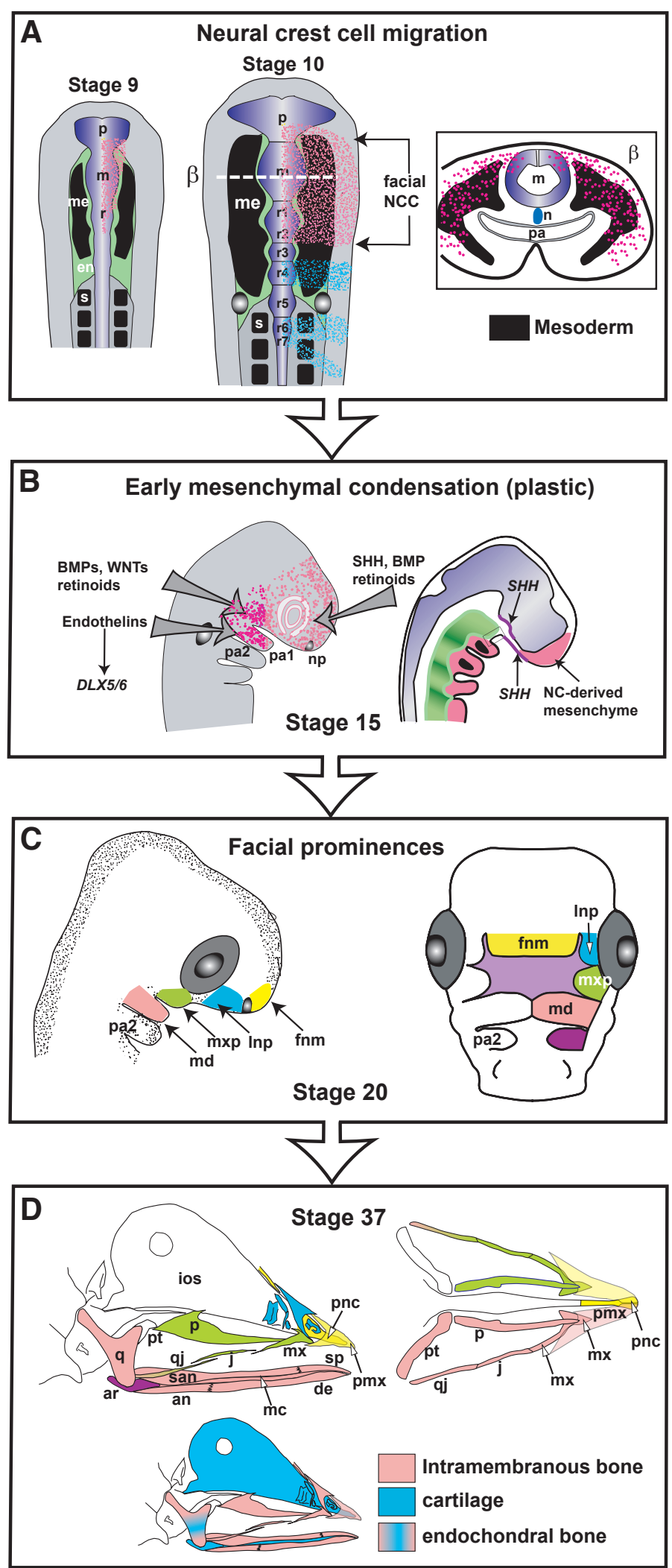
is continuous with and is likely mixing with post-optic mesenchyme. At later stages (stage 24), once the maxillary prominences have formed, there is no more mixing of cells and maxillary cells only contribute to the palate skeleton (Lee et al., 2004). Our work agrees with that of others (Cerny et al., 2004, Shigetani et al., 2000, Tak et al., 2017) that locally, at the maxillo-mandibular cleft, there is movement of cells between the first arch and presumptive maxillary prominence. This sharing of mesenchyme between the future proximal maxillary and mandibular prominence may explain why the global transcriptomes of these two regions are more similar to each other than to that of the frontonasal mass (Buchtova et al., 2010).

Jaw identity is being established during pharyngeal arch development. The post-migratory neural crest-derived mesenchyme in the presumptive face continues to interact with local tissues (epithelium, endoderm) to gradually give rise to characteristic patterns of the upper and lower beak. Experiments that target facial mesenchyme after neural crest cell migration has ceased, but before individual facial prominences have formed, can induce a change in identity from maxillary prominence to frontonasal mass (Cela et al., 2016, Lee et al., 2001, Nimmagadda et al., 2015). We will discuss the signals involved in specification of neural crest-derived skeleton later in this review.

\section{Brain face interactions - the chicken forebrain signals to the face}

Due to the close proximity of brain and face, the brain has long been suspected of being an important signaling center that controls facial development (Demyer et al., 1964). Recently, the molecular underpinnings of these interactions have been teased apart using the chicken embryo as a study system. The main molecule involved in this interaction is Sonic Hedgehog (SHH). The earliest SHHsignals come from the prechordal plate, which then turns on expression of $\mathrm{SHH}$ in the ventral diencephalon between 6 and 8 somite stages (stage 7) (Brito et al., 2006). If the forebrain is excised after the induction of $\mathrm{SHH}$ in the diencephalon, only the lower beak forms. However, the addition of a SHH soaked bead to an embryo lacking the forebrain restores the upper beak. This experiment proves that $\mathrm{SHH}$ is necessary and sufficient for upper beak formation.

In another series of experiments on slightly older embryos (stage 10), signaling from the forebrain was inhibited by injecting hybridoma cells secreting a SHH-blocking antibody (Marcucio et al., 2005, Young et al., 2010). The cells were injected into the lumen of the neural tube in order to specifically interfere with the brain-derived $\mathrm{SHH}$, rather than that of the foregut or prechordal plate. The treated embryos exhibited a shortened premaxilla, absence of the prenasal cartilage, smaller and medially fused maxillary bones, and smaller and medially shifted palatine bones.

The mechanism by which SHH affects the development of the upper face appears to be indirect. The absence of signaling from the brain reduces cell proliferation within the neural crest cell-derived mesenchyme, leading to developmental defects of the upper beak (Marcucio et al., 2005). However, there was also concomitant loss of SHHexpression in the frontonasal ectoderm, as well as decreases in target genes of SHH such as PTC1 and GL/1, in both the ectoderm and adjacent mesenchyme. The aforementioned changes, particularly the loss of $\mathrm{SHH}$ in the ectoderm could also have contributed to decreased proliferation. As we will discuss later, the ectoderm is required for craniofacial growth.

\section{The nasal placodes are signaling centers for the upper face}

An interesting hypothesis, which has recently been gaining experimental support, is that the cranial sensory placodes may serve as organizing centers throughout the craniofacial region (Steventon et al., 2014). The nasal placodes, in addition to forming the olfactory neurons, provide inductive signals for the formation of the face (Szabo-Rogers et al., 2008, Szabo-Rogers et al., 2009). By placing a foil barrier on the lateral side of the nasal placode in the chicken embryo, Szabo-Rogers and colleagues showed that they could prevent signals from diffusing laterally, and thus block specification of the lateral nasal prominence (Szabo-Rogers et al., 2009). Similarly, ablating the olfactory placode at stage 15 by Nile blue sulfate epithelial-stripping prevented formation of the lateral nasal bone and nasal turbinates (Szabo-Rogers et al., 2009).

The nasal placodes have surprising instructive properties as well. When grafted to an ectopic, Hox-negative region of the head, the nasal pits induced supernumerary frontonasal structures and furthermore, did not repress normally occurring skeletal elements (Szabo-Rogers et al., 2009). An earlier study also showed that the olfactory placode is able to form thickened epithelium and neurons in ectopic locations (Bhattacharyya and Bronner-Fraser, 2008). However skeletal changes were not recorded because the endpoint was prior to skeletogenesis. Our study, on the other hand, followed the placodes up to stage 37 and identified characteristic olfactory invaginations in the head as well as accompanying skeletal changes in an ectopic location. Such cut and paste experiments are ideal for testing the instructive properties of a tissue and the supportive nature of the host environment to allow continued development.

\section{Facial prominences formation, fusion and fate}

Formation of the face is a complex and precisely timed morphogenetic event that takes place between stages 20-29 in the chicken embryo. After the nasal placodes have formed, they begin to invaginate at stage 20 , while the adjacent mesenchyme proliferates to form the craniofacial prominences (Fig. 1C, Fig. 2). The facial prominences bud around the primitive oral cavity (stomodeum), and will eventually grow and fuse with each other to form the intact face. These facial prominences consist of the frontonasal mass (between the nasal placodes), paired lateral nasal prominences (lateral to the nasal placodes), maxillary prominences (lateral to the stomodeum) and the mandibular prominence (inferior to the stomodeum). At stage 27 , the prominences have grown out enough to initiate contact. In chicken, the maxillary prominences meet with the distal corners of the frontonasal mass ('globular processes'in chicken or 'medial nasal prominences' in mammals), in order to form a continuous upper lip (Fig. 2B) (Abramyan and Richman, 2015, Abramyan et al., 2015). When prominences make contact, a transient, bilayered epithelial seam (or nasal fin) forms between them, breaking down relatively quickly, and allowing for mesenchymal continuity between distinct prominences (Abramyan and Richman, 2015). Next, the grooves or furrows between the newly fused prominences fill out through a process of merging, to create a smooth surface (Abramyan and Richman, 2015).

The meeting, fusion and merging of craniofacial prominences represents a critical period of development across amniotes. If contact is abnormal, then a cleft will result in the developing upper lip, which 
may extend into the palate. Perturbation such as displacement of facial prominences in relation to each other could make it difficult for facial prominences to meet, thus there is strict conservation of morphology across amniotes at "pre-fusion" developmental stages (Young et al., 2014). Nonetheless, we have previously identified variation in the prominences between amniote lineages, adding an extra degree of difficulty in predicting developmental defects resulting from misalignment (Abramyan et al., 2015). Fortunately, humans and chickens utilize the maxillary prominence and the medial nasal/globular processes to make initial contact, making chicken an appropriate model for studies of human clefting (Abramyan et al., 2015).

Each facial prominence has a distinct contribution to the skeleton of the jaw. Pioneering transplantation experiments, where components of the embryonic face were grafted onto host limb buds, allowed a fate map of facial prominences to be determined. The frontonasal mass forms the prenasal cartilage, nasal septum, premaxillary bone and ectodermally-derived egg tooth (Richman and Tickle, 1989, Richman and Tickle, 1992, Wedden, 1987). The maxillary prominences form the bones of the palate (maxillary, palatine) as well as the jugal bone (Lee et al., 2004). The mandibular prominences form the entire mandibular bone, Meckel's cartilage, and the malleus and incus (Richman and Tickle, 1989, Wedden, 1987). The lateral nasal prominences form the nasal conchae (MacDonald et al., 2004) (Fig. 1D).

Through epithelial-mesenchymal exchange experiments between facial prominences, it became clear that jaw identity was determined by the mesenchyme, whereas the epithelium is required for outgrowth (MacDonald etal., 2004, Richman and Tickle, 1989, Wedden, 1987). Another demonstration of the role for epithelium in outgrowth was identified by some elegant grafting experiments performed by $\mathrm{Hu}$ and colleagues (Hu et al., 2003). Small strips of frontonasal mass epithelium containing the caudal edge were grafted to the lateral surface of the frontonasal mass or the mandibular prominence. In both cases, branches of the normal skeleton were produced $\mathrm{Hu}$ et al., 2003). This frontonasal ectodermal zone is also an important region for species-specific differences in the form of the midface (Hu and Marcucio, 2009b, Xu et al., 2015).

\section{Proliferation, polarity and other mechanisms driving facial prominence morphogenesis}

Facial prominences dramatically change shape during stages when lip fusion is taking place. The frontonasal mass becomes narrower medio-laterally (Fig. $2 \mathrm{~A}-\mathrm{C}$ ) and extends in the perpendicular axes (dorso-ventral, cranio-caudal). The maxillary prominences elongate cranio-caudally (Geetha-Loganathan et al., 2014). Proliferation accounts for the enlargement of the prominences but not entirely for the changes in shape. Minkoff and Kuntz carried out some of the original work on cell proliferation in the face, using the chicken embryo as a model (Minkoff and Kuntz, 1977, Minkoff and Kuntz, 1978). They showed that at stage 20, proliferation was similar in all regions of the mesenchyme but then at stage 24-25, the rate of proliferation decreased at the base of the facial prominence, leading to a relatively higher level remaining in the distal parts of the mesenchyme. Such differential proliferation was also described during chicken limb bud outgrowth (Searls and Janners, 1971), as well as the medial side of the maxillary prominences in the chicken embryo (Abramyan et al., 2014), leading to palatal shelf formation and outgrowth. Thus a relative drop in proliferation in adjacent mesenchyme explains most of the outgrowth of facial prominences (rather than a localized addition of cells to the tip). Indeed when the proliferation gradient in the maxillary prominence was disrupted through WNT11 overexpression in the maxillary mesenchyme, the maxillary buds were smaller in volume, due to a decrease in length in the cranial caudal axis (Geetha-Loganathan et al., 2014). Similarly, introduction of Noggin protein into the maxillary prominence also decreased proliferation, causing a gap to form between the frontonasal mass and maxillary prominence (Ashique et al., 2002).

Despite observation of proliferation gradients, early hypotheses assumed that proliferation, which was driving morphogenesis of facial prominences, was undirected and isotropic (Linde-Medina et al., 2016). These traditional models must now accommodate new data identifying cell polarity as a significant part of facial prominence budding and outgrowth (Geetha-Loganathan et al., 2014, Li et al., 2013). In a study of the frontonasal mass, Li et al., quantified polarity in mesenchymal cells by analyzing the position of the nucleus and the Golgi body. Through analysis of static images, they showed that the mesenchymal cells located in the lateral regions of the frontonasal mass were oriented toward the points of outgrowth (i.e. the globular processes) (Geetha-Loganathan et al., 2014, Li et al., 2013). In the maxillary prominence, we utilized measurement of the angle formed by cell's major axis and a reference line to show that cells were preferentially oriented $\sim 30$ degrees medial to the cranial-caudal axis (Geetha-Loganathan et al., 2014). In functional experiments performed in vivo, we also showed that the mesenchymal cells will reorient themselves and migrate toward an ectopic source of WNT11. These experiments demonstrated that directional cues, in addition to proliferation, are likely required to drive growth of prominences towards a larger size, the correct
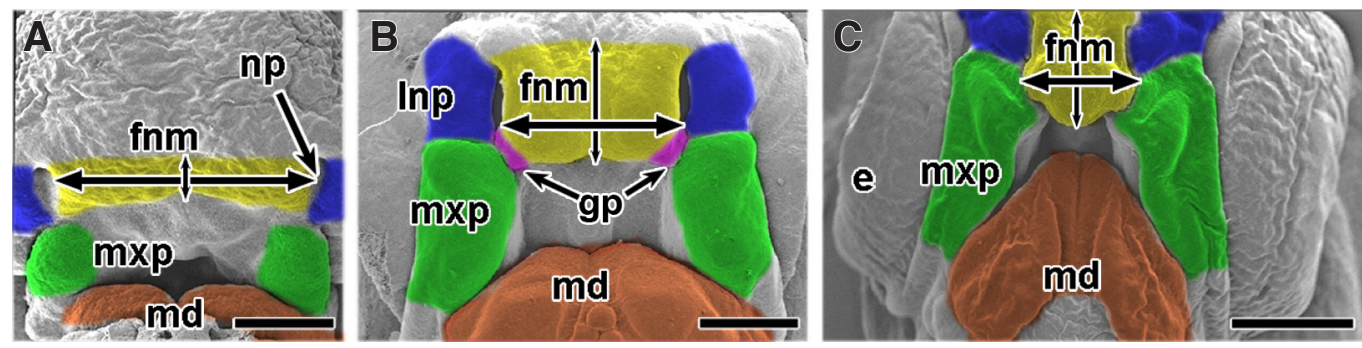

Fig. 2. Craniofacial prominences in the developing chicken. Scanning electron micrographs of the chicken face. The facial prominences change proportions between stage 20(A), 3.5 days; stage 24 (B), 4.5 daysand stage 29 (C), 6 days. Note the mediolateral

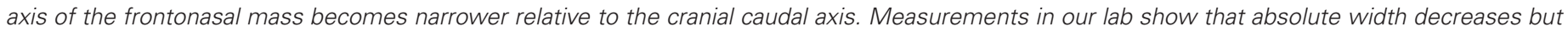

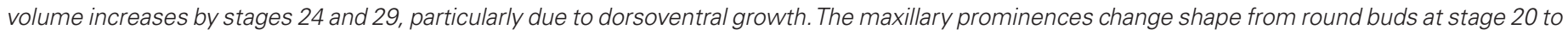

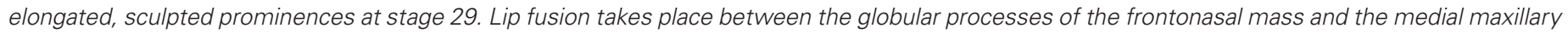

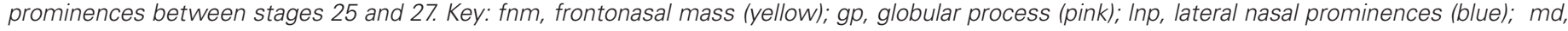
mandibular prominences (orange); mxp, maxillary prominences (green). Scale bar, 500 um for stage 20 and $24 ; 1$ mm for stage 29. 
shape, and in the right direction.

In thinking about growth and morphogenesis during development, most developmental biologist focus on the behavior of cells, while the extracellular matrix is generally ignored. In an immunofluorescence study on chicken embryos, Xu et al. found that the basement membrane is thinner in regions that undergo extensive shape changes. It makes sense that the basement membrane would have to facilitate budding though mechanical compliance, however this model has not yet been tested functionally in the face (Xu et al., 1990).

Other mechanisms of facial prominence morphogenesis could involve mesenchymal cell rearrangements. This idea has thus far only been studied using Dil injections and static imaging. Since the embryonic face of the chicken is turned on its side (in ovo), data are mainly available for the accessible, lateral nasal prominence, maxillary prominence, lateral frontonasal mass and mandibular prominence (Lee et al., 2004, McGonnell et al., 1998)
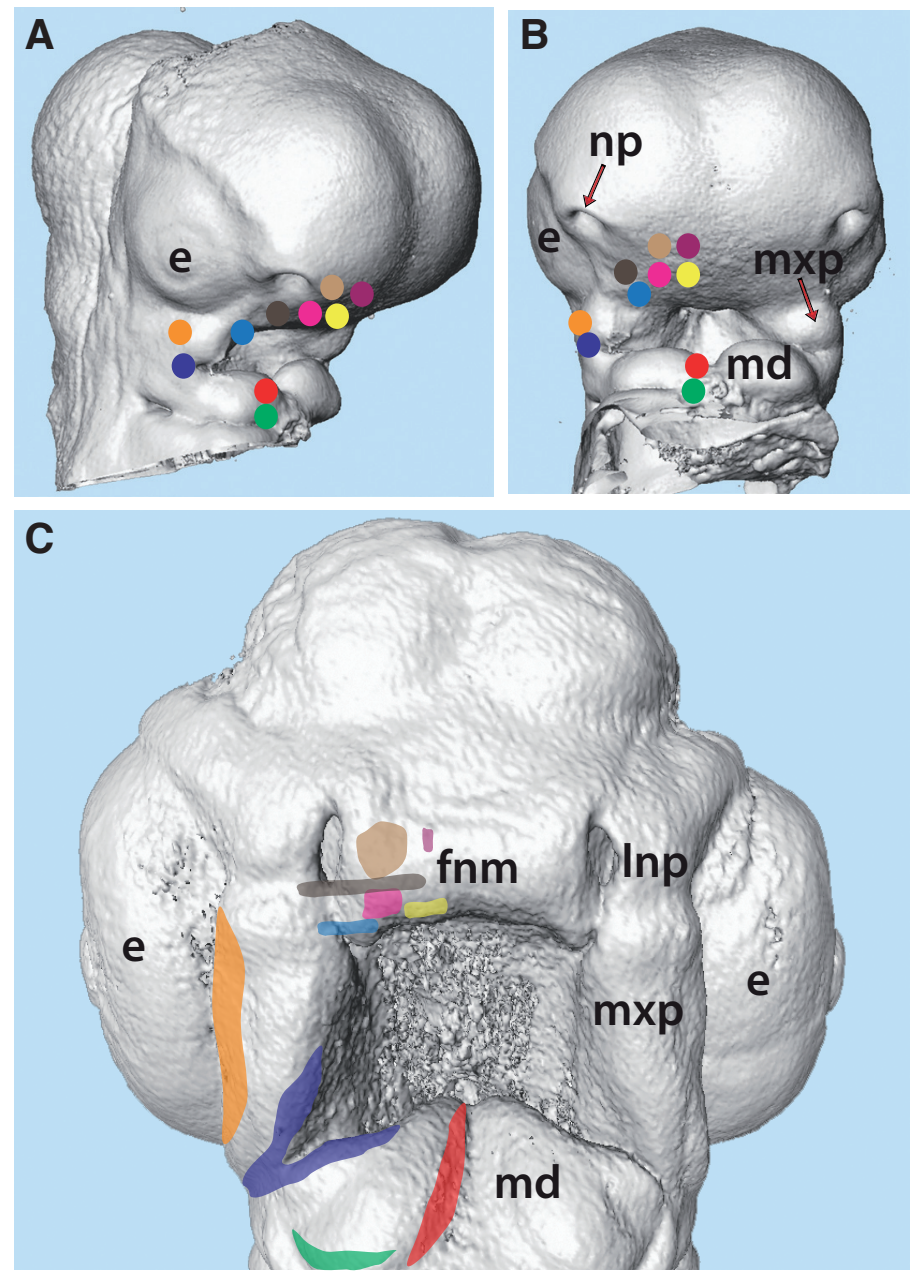

Fig. 3. Summary illustration of experiments from McGonnell et al., 1998. Optical projection tomography scans of chicken embryo heads. Isosurfaces were generated using Amira software. (A,B) Side and frontal views of stage 20 embryos with injection sites color coded in each of the facial prominences. (C) Stage 28 embryo illustrating the various shapes formed by the expanded Dil, 48h after injection at stage 28. Abbreviations: e, eye; fnm, frontonasal mass; Inp, lateral nasal prominence; $m$ d, mandible; mxp, maxillary prominence; $n p$, nasal pit.
(Fig. 3). The focally labeled regions expand over the $48 \mathrm{~h}$ of the experiment due to displacement, migration and cell proliferation. In the lateral maxillary prominence the cells spread out next to the eyes (McGonnell et al., 1998), similar to what we found in transfection experiments (Geetha-Loganathan et al., 2014). The cells labeled at the maxillo-mandibular cleft are distributed on either side of the cleft (McGonnell et al., 1998, Tak et al., 2017). The mandible also has some interesting patterns of cell expansion correlating with beak outgrowth. The midline mesenchyme spreads in a line following the cranial-caudal axis. Mesenchyme near the second pharyngeal arch spread in the medio-lateral plane (Fig. 3). However, more work needs to be done to determine whether these Dil patterns correspond to directed cell movement, oriented cell division or differential proliferation. Dil cannot label individual cells. Therefore, our lab is currently developing live imaging methods to track single mesenchymal cells in the face during organogenesis stages.

\section{Signaling during facial morphogenesis}

The implantation of beads that are soaked in agonists and antagonists have been used extensively to examine the roles of signaling molecules such as retinoic acid ( $\mathrm{RA}), \mathrm{SHH}$, fibroblast growth factors (FGF), wingless related factors (WNTs) and bone morphogenetic proteins (BMPs) during many stages of craniofacial development. Here we will focus on facial prominence growth and lip fusion.

\section{Sonic hedgehog (SHH)}

SHHRNA is expressed in epithelium covering the stomodeum and extends to the caudal edge of the frontonasal mass and medial surface of the maxillary prominences (Ashique et al., 2002, Marcucio et al., 2005). Application of beads soaked in a blocking antibody for SHH into the frontonasal mass caused cleft lip in the chicken embryo (Hu and Helms, 1999). Similarly, a more recent approach where electroporation was used to block SHH-signaling specifically in the epithelium also caused clefting (Hu et al., 2015). Therefore, it is likely that the epithelium-derived $\mathrm{SHH}$ is required for outgrowth of the frontonasal mass, which is itself a requirement for contact and fusion with the maxillary prominence in order to form an intact upper lip. An increase in $\mathrm{SHH}$ levels either in the brain (Hu and Marcucio, 2009b) or directly in the frontonasal mass (Hu and Helms, 1999), was found to have opposite effects. Direct application to the frontonasal mass caused it to become slightly wider, but ultimately major skeletal defects were not observed (Hu and Helms, 1999). When SHH-soaked beads were placed in the brain, the frontonasal mass again grew wider (Young et al., 2010), but upper beak was significantly shorter due in part to a decrease in proliferation (Hu and Marcucio, 2009b). This result is slightly difficult to explain, since normally $\mathrm{SHH}$ promotes cell survival as well as expression of $\mathrm{SHH}$ in the frontonasal mass epithelium. Both of these outcomes should have resulted in a wider prenasal cartilage. Indeed, a more sustained delivery of $\mathrm{SHH}$ via a retrovirus within the frontonasal mass caused a bifurcation of the prenasal cartilage and duplication of the egg tooth ( $\mathrm{Hu}$ and Helms, 1999). Thus it seems that $\mathrm{SHH}$ signals coming from the brain are received differently in the frontonasal mass than when supplied directly in the facial mesenchyme. The fact that excess $\mathrm{SHH}$ causes a different set of craniofacial deficiencies from the 
two types of manipulations may also be due to stage-specific differences in the mesenchymal response.

\section{Bone morphogenetic proteins (BMPs)}

Studies of chicken craniofacial development from our lab have implicated BMPs as major players in lip fusion (Ashique et al., 2002). BMP2 was found to be abundant in the globular process mesenchyme as well as the maxillary prominences (Ashique et al., 2002, Francis-West et al., 1994). BMP4 and BMP7 were largely localized in the epithelium. NOGGIN (NOG), a BMP antagonist, was expressed in epithelial tissue surrounding the globular process at stage 24 , but then was downregulated at stage 28 . This curious change in expression of NOG coincides with the time when the bilayered epithelial seam forms between the frontonasal mass and maxillary prominences. When beads soaked in exogenous NOGGIN protein were implanted into to the globular process to keep NOGGIN levels high, the epithelium became thicker. The increase in cell survival in the epithelium could also have interfered with fusion, had the facial prominences contacted each other, since the degradation of the epithelial seam is a key component of fusion. Concomitant with the epithelial thickening, a reduction in proliferation of the mesenchyme was observed, ultimately leading to a cleft of the upper beak in a similar anatomical position to human cleft lip. These subtle changes are visible in bead-implanted embryos because the diffusion of the protein is only $100-200 \mu \mathrm{m}$ from the bead. Thus the study of a process that is very local, like lip fusion, is ideally suited for the bead implant approach.

\section{Fibroblast growth factors (FGFs)}

FGF signaling is critical for a number of proliferative zones in the developing face. Studies from our lab (Szabo-Rogers et al., 2008, Szabo-Rogers et al., 2009) have determined that molecular signals including FGF8 from the nasal pit are necessary for patterning the lateral nasal prominence and frontonasal mass. By implanting beads soaked in a pan-antagonist of FGF receptors (SU5402), we were able to show that proliferative growth had a surprising degree of dependence on FGF signals in some areas of the face and while none at all in others (Szabo-Rogers et al., 2008). A cleft was induced when FGF signaling was disturbed in the cranial part of the prominence. Most unexpectedly, we found that FGF signaling was dispensable in the globular process of the frontonasal mass and medial corner of the maxillary prominence, which are the two regions critical for the process of primary palate fusion (Szabo-Rogers et al., 2008). We concluded that proliferation in the cranial frontonasal mass mesenchyme displaced the globular process caudally, promoting contact with the maxillary prominence. Experiments from others showed that inhibition of FGF signaling in the centre of the frontonasal mass at stage 17 shortened the upper beak and also induced a cleft (Hu and Marcucio, 2009a), confirming the general requirement for FGF in outgrowth of the mesenchyme. Other studies also demonstrated a role for epithelial-derived FGF signaling in regulating frontonasal mass transcriptional responses (Firnberg and Neubuser, 2002).

FGF signaling is also a major element in the formation of the discrete region of facial ectoderm in the chicken embryo such as the frontonasal ectodermal zone (Hu et al., 2003). FGF8 is required for initial frontal ectodermal zone activity (Hu et al., 2003), but other data indicate that FGF8 needs to be downregulated for normal development of the frontonasal region of the head (MacDonald et al.,
2004). While FGF8 on its own is not sufficient to induce outgrowths of the frontonasal mass (Hu et al., 2003), the combination of FGF8 and $\mathrm{SHHectopic} \mathrm{expression} \mathrm{in} \mathrm{the} \mathrm{head} \mathrm{epithelium} \mathrm{induces} \mathrm{ectopic}$ outgrowths supported by cartilage (Abzhanov and Tabin, 2004). The frontonasal epithelial zone secretes multiple genes in addition to FGF8 and SHH such as BMP4 and NOG (Ashique et al., 2002) all of which may contribute to upper beak outgrowth.

\section{Wingless-type MMTV integration site (WNTs)}

We performed a comprehensive characterization of WNT pathway genes in the chicken embryo in preparation for future functional studies (Geetha-Loganathan etal., 2009). We analyzed the expression of a number of WNT paralogs, as well as other genes within the WNT pathway such as the DKK family of antagonists, the FZD family of receptors, as well as the signal transduction molecule CTNNB1 and the transcriptional target, LEF1. We examined the roles of WNT5A in the development of the chicken skull due to its high level of expression in the frontonasal mass, maxillary and mandibular prominence mesenchyme (Hosseini-Farahabadi et al., 2013). Previous chicken studies had exclusively focused on the function of WNT5A on the appendicular and axial skeletons (Hartman and Tabin, 2000). Through a series of in vivo and in vitro experiments, we showed that WNT5A represses canonical WNT signaling on order to allow for the differentiation of craniofacial cartilage. In a recent study, the overexpression of WNT5A in vivo was characterized in more detail and compared to mutant version of the gene that causes Robinow syndrome (Hosseini-Farahabadi et al., 2017). Patients with a single allele containing the WNT5A variants have major craniofacial and limb anomalies (Person et al., 2010, Roifman et al., 2014). We were able to use the chicken to determine the pathogenicity of 2 missense variants affecting a cysteine residue in WNT5A. The wild-type and mutant human WNT5A genes introduced into the chicken mandibular prominence caused shortening of the structure. Specifically, the mutant version of WNT5A randomized the orientation of Meckel's cartilage chondrocytes. These cell orientation defects, along with reduced cell migration, suggested there were problems in the JNK-planar cell polarity pathway (one of the non-canonical WNT pathways). This study suggests that normal WNT5A signaling is needed for proper chondrocyte stacking in order that Meckel's cartilage elongates.

WNT11 is another putative non-canonical WNT, which we had previously identified as being highly expressed in the maxillary prominences (Geetha-Loganathan et al., 2009). Through a series of knockdown and overexpression experiments, we found that WNT11 induces a decrease in cell proliferation, thereby preventing lengthening of the facial prominences and inducing a cleft in the developing beak. In this study, we also uncovered a novel role for the WNT11 molecule, showing that it can behave as a chemoattractant to cells in the developing craniofacial prominences. Through detailed analysis of cell migration, cell orientation, as well as luciferase assay data, we showed that WNT11, similar to WNT5A, is capable of activating a planar cell polarity (PCP)-type of mechanisms in the facial mesenchyme cells (Geetha-Loganathan et al., 2014).

\section{Retinoic acid (RA)}

The first molecule tested in a local release experiment in the chicken embryo was RA (Tickle et al., 1982). At the same time as digit duplications were induced, the upper beak was unexpectedly, 
completely truncated (Tamarin et al., 1984). The molecular reasons for the upper beak defect were never discovered, but it was clear from epithelial-mesenchymal exchanges between treated and untreated embryos that the main target of RA was the mesenchyme (Wedden, 1987).

Excess RA provides insights into the teratogenic properties of this molecule. However endogenous RA is also required for development. Earlier studies from our lab utilized Citral-soaked beads (a general antagonist of RA synthesis) (Song et al., 2004). Treatment of stage 20 chicken embryos resulted in the loss of derivatives from the lateral nasal prominences. Specifically, resulting in the absence of the nasal bone and nasal conchae. We were able to show that the Citral-induced phenotype was due to reduction in RA synthesis and FGF8 expression. Exogenous FGF8 or RA application rescued the Citral induced phenotype, implicating FGF8 as a regulator of cell survival in the developing face.

\section{Cross talk between the retinoic acid and bone morphogenetic protein pahways}

RA and NOGGIN protein soaked beads placed into the first pharyngeal arch of stage 15 chicken embryos resulted in an unexpected facial phenotype. The maxilla was transformed into a second frontonasal mass; ultimately leading to a partial duplication of the upper beak (Lee et al., 2001, Nimmagadda et al., 2015). The ectopic skeletal elements were located in the palate and consisted of a duplicated interorbital septum, prenasal cartilage and premaxilla. The identity of the transformation was unambiguous due to formation of an ectopic egg tooth (exclusively found on the frontonasal mass). In subsequent studies, NOGGIN protein with greater bioactivity was obtained (Regeneron) and this baculovirus-derived protein was sufficient on its own to drive the formation of an ectopic interorbital septum, prenasal cartilage, premaxilla and egg tooth (Cela et al., 2016). We carried out a gene profiling experiment and found novel mediators of RA signaling (Nimmagadda et al., 2015). We also discovered cross talk between NOGGIN and RA. NOGGIN itself was able to induce several RA pathway molecules, further increasing the levels of endogenous RA synthesis (Nimmagadda et al., 2015). This ability of NOGGIN to activate RA signaling may explain why NOGGIN on its own could elicit the same phenotype as NOGGIN and RA combined (Cela et al., 2016).

\section{Abnormal craniofacial development in spontaneous chicken mutants}

While development of transgenic lines has met with limited success in the chicken (with the exception of GFP lines), several spontaneous mutant lines with craniofacial anomalies exist and have been utilized by developmental biologists for several decades. Our lab has studied the cpp mutant (cleft primary palate) characterized by Ursula Abbott (MacDonald et al., 2004, Yee and Abbott, 1978). The cpp mutant carries an unknown recessive mutation that causes upper beak truncation, not dissimilar to the effects of excess RA. A particular challenge with studying the cpp mutant is that the mutant phenotype is first manifested at stage 28 , which is relatively late in development. To identify mutants at earlier stages, the affected tissue was divided into pieces and grafts were made to host embryos. The normal frontonasal mass gave rise to long cartilage rods whereas the mutant frontonasal mass only formed short nodules of cartilage. Through blind tissue recombination experiments, we determined that the mutation specifically affects the epithelium (MacDonald et al., 2004). The tissue recombination method provides unique information that cannot necessarily be predicted from the genetic sequence. It is a challenge to identify the spontaneous mutations in chicken embryos due to outbreeding that has to be done to keep genetic lines robust (J. Pisenti, UC Davis, personal communication).

The talpid mutants [talpid, talpid2 (ta2), talpid3 (ta3)] are categorized together due to their shared phenotype of polydactyly and severe craniofacial malformations (Schock et al., 2016). After many years of work, the Edinburgh group who spearheaded many of the early efforts to create genomic resources for the chicken, finally mapped and identified the gene underlying the talpid3 line (KIAA0586) (Davey et al., 2006, Yin et al., 2009). The ta2 mutation was later identified in the USA (Chang et al., 2014) as being caused by deletions in the $C 2 C D 3$ gene. Interestingly, ta2 has a relatively mild craniofacial phenotype where the facial prominences fail to fuse properly, resulting in a cleft of the primary palate, while ta3 mutants exhibit a collapse of the facial midline (through reduction of brain floorplate $\mathrm{SHH}$ ), resulting in hypotelorism (Schock et al., 2016)). Importantly, both of these mutations affect the primary cilia which may explain the similar phenotypes. The chicken mutations ended up affecting the same genes as 2 human craniofacial ciliopathies: Oral-facial-digital syndrome (ta2) (Schock et al., 2015) and Joubert syndrome Joubert Syndrome (JS) (ta3) (Stephen et al., 2013). Thus the chicken embryo once again proves to be a useful model in which to study human genetic disease.

\section{The chicken beak in studies of evolutionary biology}

Avian beaks exhibit immense diversity in shape and size, ranging from relatively small beaks of tits and chickadees of the Paridae family to the extensive beaks of hornbills and toucans. As we previously mentioned, morphological diversity is highly reduced in the craniofacial region of amniote embryos (Young et al., 2014), yet we were able to identify some minor, lineage-specific changes in craniofacial prominence shape, position, and points of fusion (Abramyan and Richman, 2015, Abramyan etal., 2015). By studying primary palatogenesis in the chicken embryo in 3D morphospace, we found that chickens (along with squamates and turtles) form their primary palate across a patent 'choanal groove' that remains open throughout development (Abramyan et al., 2015). A literature search of studies from the early $20^{\text {th }}$ century found that this was also the case in lungfishes and amphibians, suggesting that mammals have a unique, derived character in the transient closure of their choanae during the fusion of their upper lip (Abramyan et al., 2015) while birds retain the ancestral developmental pattern.

At stages following primary palatogenesis, Abzhanov and Tabin performed studies of the natural variation in beak size and shape amongst Galapagos Island finches (Abzhanov et al., 2004). As a classical example of adaptive evolution, Galapagos finches exhibit a gradation in beak size and shape, ranging from the ground finches which have deep and wide beaks, to the fine-beaked cactus finches. Even before phenotypic variation could be observed, BMP4 expression appears to differ in the two groups (Abzhanov et al., 2004). By using the chicken embryos as an experimental model, they showed that excess BMP4 can indeed induce an ectopic "growth zone" through increased cell proliferation, resulting in the conversion of the relatively narrow and short chicken beak 
into much broader, deeper beak that resembled the bulky Ground finch beak (Abzhanov et al., 2004). Later studies of growth zones in songbird beaks showed that while they provide the basis for variation in shape, they also constrain the shape of the beak to a limited morphological parameter space (Fritz et al., 2014).

Chuong and colleagues also studied cellular proliferation and gene expression that underlie differences in beak shape, this time between the chicken, duck and cockatiel (Wu et al., 2004). They identified zones with higher mesenchymal proliferation, which they called 'localized growth zones', within the frontonasal mass. At stage 28, the two growth zone in the frontonasal mass converged in the chicken embryo while remaining separate in the duck (Wu et al., 2004); causing prolonged lateral growth in the wider duck bill as compared to the chicken. These authors also found that an increase or decrease in BMP signaling (BMP4 expression in particular) was responsible for the disparity in break size and shape between the duck and chicken (Wu et al., 2004). In a second study, Wu et al. (2006) found that the curvature of the beak correlates with proliferation patterns. The relatively flat and broad duck bill mainly exhibits distal proliferation, while the cockatiel beak exhibits maximal proliferation proximally; resulting in the strong downward curvature characteristic of parrots (Wu et al., 2006). Epithelial gene expression also differed in temporal patterns. FGF8 is typically downregulated in the chicken frontonasal mass after stage 20 (Higashihori et al., 2010) but persists in the duck up to stage 23 (Wu et al., 2006). The aforementioned studies on birds suggest that minor alterations in the spatiotemporal regulation of signaling molecules (e.g. FGFs, WNTs, SHH, BMPs) is sufficient to evolve novel beak shapes. The use of chicken as a model in evolutionary developmental biology has even extended to analysis of frontonasal architecture across Archosaurs, the ancestral group that includes dinosaurs. By manipulating the midline WNT responsiveness in the chicken frontonasal mass, Bhullar and colleagues were able to change the shape of premaxillae and palatine to more of an ancestral shape, resembling crocodilians and extinct archosaurs (Bhullar et al., 2015). Thus experimental studies on birds can also be used to model evolution of the jaws in non-avian reptiles as well.

\section{Concluding remarks}

Fortunately, natural selection has obligated early stages of development to remain constrained across amniotes, allowing for the broad use of a large number of non-human models in better understand human disease. Indeed the chicken embryo frontonasal mass resembles the human embryo far more than the mouse, which has a very deep midline furrow. The chicken is a low cost model which permits the accumulation of many replicates, something that is difficult to achieve in the mouse. Even though there is variation due to technical issues (bead placement, slight stage differences etc.), a large number of embryos can be collected, increasing the experimental rigor. The power of the chicken embryo is that all steps can be followed easily, thereby connecting genes or signals to phenotypes. Even though the chicken is not a genetic model, there is still great promise in using this avian model to test the pathogenicity of human DNA variants causing a variety of structural birth defects. Therefore we are confident that the chicken will complement the work being done in the mouse and zebrafish and will retain its place as a model organism for craniofacial development.

\section{References}

ABRAMYAN, J., LEUNG, K.J. and RICHMAN, J.M. (2014). Divergent palate morphology in turtles and birds correlates with differences in proliferation and BMP2 expression during embryonic development. J Exp Zool B Mol Dev Evol322: 73-85.

ABRAMYAN, J. and RICHMAN, J.M. (2015). Recent insights into the morphological diversity in the amniote primary and secondary palates. Dev Dyn 244: 1457-1468.

ABRAMYAN, J., THIVICHON-PRINCE, B. and RICHMAN, J.M. (2015). Diversity in primary palate ontogeny of amniotes revealed with 3D imaging. JAnat226:420-433.

ABZHANOV, A., PROTAS, M., GRANT, B.R., GRANT, P.R. and TABIN, C.J. (2004). Bmp4 and morphological variation of beaks in Darwin's finches. Science 305: $1462-1465$.

ABZHANOV, A. and TABIN, C.J. (2004). Shh and Fgf8 act synergistically to drive cartilage outgrowth during cranial development. Dev Biol 273: 134-148.

ASHIQUE, A.M., FU, K. and RICHMAN, J.M. (2002). Endogenous bone morphogenetic proteins regulate outgrowth and epithelial survival during avian lip fusion. Development 129: 4647-4660.

BENOUAICHE, L., GITTON, Y., VINCENT, C., COULY, G. and LEVI, G. (2008). Sonic hedgehog signalling from foregut endoderm patterns the avian nasal capsule. Development 135: 2221-2225.

BHATTACHARYYA, S. and BRONNER-FRASER, M. (2008). Competence, specification and commitment to an olfactory placode fate. Development 135: 4165-4177.

BHULLAR, B.A., MORRIS, Z.S., SEFTON, E.M., TOK, A., TOKITA, M., NAMKOONG, B., CAMACHO, J., BURNHAM, D.A. and ABZHANOV, A. (2015). A molecular mechanism for the origin of a key evolutionary innovation, the bird beak and palate, revealed by an integrative approach to major transitions in vertebrate history. Evolution 69: 1665-1677.

BOND, S.R., ABRAMYAN, J., FU, K., NAUS, C.C. and RICHMAN, J.M. (2016). Pannexin 3 is required for late stage bone growth but not for initiation of ossification in avian embryos. Dev Dyn 245: 913-924.

BRITO, J.M., TEILLET, M.A. and LE DOUARIN, N.M. (2006). An early role for sonic hedgehog from foregut endoderm in jaw development: ensuring neural crest cell survival. Proc Natl Acad Sci USA 103: 11607-11612.

BUCHTOVA, M., KUO, W.P., NIMMAGADDA, S., BENSON, S.L., GEETHA-LOGANATHAN, P., LOGAN, C., AU-YEUNG, T., CHIANG, E., FU, K. and RICHMAN, J.M. (2010). Whole genome microarray analysis of chicken embryo facial prominences. Dev Dyn 239: 574-591.

CELA, P., BUCHTOVA, M., VESELA, I., FU, K., BOGARDI, J.P., SONG, Y., BARLOW, A., BUXTON, P., MEDALOVA, J., FRANCIS-WEST, P. et al., (2016). BMP signaling regulates the fate of chondro-osteoprogenitor cells in facial mesenchyme in a stage-specific manner. Dev Dyn 245: 947-962.

CERNY, R., LWIGALE, P., ERICSSON, R., MEULEMANS, D., EPPERLEIN, H.H. and BRONNER-FRASER, M. (2004). Developmental origins and evolution of jaws: new interpretation of "maxillary" and "mandibular". Dev Biol 276: 225-236.

CHANG, C.F., SCHOCK, E.N., O'HARE, E.A., DODGSON, J., CHENG, H.H., MUIR, W.M., EDELMANN, R.E., DELANY, M.E. and BRUGMANN, S.A. (2014). The cellular and molecular etiology of the craniofacial defects in the avian ciliopathic mutant talpid2. Development 141: 3003-3012.

COULY, G., CREUZET, S., BENNACEUR, S., VINCENT, C. and LE DOUARIN, N.M. (2002). Interactions between Hox-negative cephalic neural crest cells and the foregut endoderm in patterning the facial skeleton in the vertebrate head. Development 129: 1061-1073.

COULY, G., GRAPIN-BOTTON, A., COLTEY, P. and LE DOUARIN, N.M. (1996). The regeneration of the cephalic neural crest, a problem revisited: the regenerating cells originate from the contralateral or from the anterior and posterior neural fold. Development 122: 3393-3407.

COULY, G.F., COLTEY, P.M. and LE DOUARIN, N.M. (1993). The triple origin of skull in higher vertebrates: a study in quail-chick chimeras. Development 117: 409-429.

CREUZET, S., COULY, G. and LE DOUARIN, N.M. (2005). Patterning the neural crest derivatives during development of the vertebrate head: insights from avian studies. J Anat 207: 447-459.

CREUZET, S., COULY, G., VINCENT, C. and LE DOUARIN, N.M. (2002). Negative effect of Hox gene expression on the development of the neural crest-derived facial skeleton. Development 129: 4301-4313.

DAVEY, M.G., PATON, I.R., YIN, Y., SCHMIDT, M., BANGS, F.K., MORRICE, D.R., 
SMITH, T.G., BUXTON, P., STAMATAKI, D., TANAKA, M. et al., (2006). The chicken talpid3 gene encodes a novel protein essential for Hedgehog signaling. Genes Dev 20: 1365-1377.

DEMYER, W., ZEMAN, W. and PALMER, C.G. (1964). The Face Predicts the Brain: Diagnostic Significance of Median Facial Anomalies for Holoprosencephaly (Arhinencephaly). Pediatrics 34: 256-263.

DEPEW, M.J. and COMPAGNUCCI, C. (2008). Tweaking the hinge and caps: testing a model of the organization of jaws. J Exp Zool B Mol Dev Evol 310: 315-335.

EAMES, B.F. and SCHNEIDER, R.A. (2008). The genesis of cartilage size and shape during development and evolution. Development 135: 3947-3958.

EAMES, B.F., SHARPE, P.T. and HELMS, J.A. (2004). Hierarchy revealed in the specification of three skeletal fates by Sox9 and Runx2. Dev Biol 274: 188-200.

FIRNBERG, N. and NEUBUSER, A. (2002). FGF signaling regulates expression of Tbx2, Erm, Pea3, and Pax3 in the early nasal region. Dev Biol 247: 237-250.

FISH, J.L., SKLAR, R.S., WORONOWICZ, K.C. and SCHNEIDER, R.A. (2014). Multiple developmental mechanisms regulate species-specific jaw size. Development 141: 674-684.

FOPPIANO, S., HU, D. and MARCUCIO, R.S. (2007). Signaling by bone morphogenetic proteins directs formation of an ectodermal signaling center that regulates craniofacial development. Dev Biol 312: 103-114.

FRANCIS-WEST, P.H., TATLA, T. and BRICKELL, P.M. (1994). Expression patterns of the bone morphogenetic protein genes Bmp-4 and Bmp-2 in the developing chick face suggest a role in outgrowth of the primordia. Dev Dyn 201: 168-178.

FRITZ, J.A., BRANCALE, J., TOKITA, M., BURNS, K.J., HAWKINS, M.B., ABZHANOV, A. and BRENNER, M.P. (2014). Shared developmental programme strongly constrains beak shape diversity in songbirds. Nat Commun 5: 3700 .

GEETHA-LOGANATHAN, P., NIMMAGADDA, S., ANTONI, L., FU, K., WHITING, C.J., FRANCIS-WEST, P. and RICHMAN, J.M. (2009). Expression of WNT signalling pathway genes during chicken craniofacial development. Dev Dyn238: 1150-1165.

GEETHA-LOGANATHAN, P., NIMMAGADDA, S., FU, K. and RICHMAN, J.M. (2014). Avian facial morphogenesis is regulated by c-Jun $\mathrm{N}$-terminal kinase/planarcell polarity (JNK/PCP) wingless-related (WNT) signaling. J Biol Chem 289: 24153-24167.

GORDON, C.T., RODDA, F.A. and FARLIE, P.G. (2009). The RCAS retroviral expression system in the study of skeletal development. Dev Dyn 238: 797-811.

GRAHAM, A. (2003). Development of the pharyngeal arches. Am J Med Genet A 119A: 251-256

HIGASHIHORI, N., BUCHTOVA, M. and RICHMAN, J.M. (2010). The function and regulation of TBX22 in avian frontonasal morphogenesis. Dev Dyn 239: 458-473.

HOSSEINI-FARAHABADI, S., GEETHA-LOGANATHAN, P., FU, K., NIMMAGADDA, S., YANG, H.J. and RICHMAN, J.M. (2013). Dual functions for WNT5A during cartilage development and in disease. Matrix Biol 32: 252-264.

HOSSEINI-FARAHABADI, S., GIGNAC, S., DANESCU, A., FU, K. and RICHMAN, J.M. (2017). Abnormal WNT5A Signaling Causes Mandibular Hypoplasia in Robinow Syndrome. J Dent Res 96: 1265-1272. (DOI: 10.1177/0022034517716916)

HU, D., COLNOT, C. and MARCUCIO, R.S. (2008). Effect of bone morphogenetic protein signaling on development of the jaw skeleton. Dev Dyn 237: 3727-3737.

HU, D. and HELMS, J.A. (1999). The role of sonic hedgehog in normal and abnormal craniofacial morphogenesis. Development 126: 4873-4884.

HU, D. and MARCUCIO, R.S. (2009a). A SHH-responsive signaling center in the forebrain regulates craniofacial morphogenesis via the facial ectoderm. Development 136: 107-116.

HU, D. and MARCUCIO, R.S. (2009b). Unique organization of the frontonasal ectodermal zone in birds and mammals. Dev Biol 325: 200-210.

HU, D., MARCUCIO, R.S. and HELMS, J.A. (2003). A zone of frontonasal ectoderm regulates patterning and growth in the face. Development 130: 1749-1758.

HU, D., YOUNG, N.M., LI, X., XU, Y., HALLGRIMSSON, B. and MARCUCIO, R.S. (2015). A dynamic Shh expression pattern, regulated by SHH and BMP signaling, coordinates fusion of primordia in the amniote face. Development 142: 567-574.

KOENTGES, G. and LUMSDEN, A. (1996). Rhombencephalic neural crest segmentation is preserved throughout craniofacial ontogeny. Development 122: 3229-3242.

KULKARNI, J.A., MYHRE, J.L., CHEN, S., TAM, Y.Y.C., DANESCU, A., RICHMAN, J.M. and CULLIS, P.R. (2017). Design of lipid nanoparticles for in vitro and in vivo delivery of plasmid DNA. Nanomedicine 13: 1377-1387.

LE LIEVRE, C.S. (1978). Participation of neural crest-derived cells in the genesis of the skull in birds. J Embryol Exp Morphol 47: 17-37.

LEE, S.H., BEDARD, O., BUCHTOVA, M., FU, K. and RICHMAN, J.M. (2004). A new origin for the maxillary jaw. Dev Biol 276: 207-224.

LEE, S.H., FU, K.K., HUI, J.N. and RICHMAN, J.M. (2001). Noggin and retinoic acid transform the identity of avian facial prominences. Nature 414: 909-912.

LI, X., YOUNG, N.M., TROPP, S., HU, D., XU, Y., HALLGRIMSSON, B. and MARCUCIO, R.S. (2013). Quantification of shape and cell polarity reveals a novel mechanism underlying malformations resulting from related FGF mutations during facial morphogenesis. Hum Mol Genet 22: 5160-5172.

MACDONALD, M.E., ABBOTT, U.K. and RICHMAN, J.M. (2004). Upper beaktruncation in chicken embryos with the cleft primary palate mutation is due to an epithelia defect in the frontonasal mass. Dev Dyn 230: 335-349.

MARCUCIO, R.S., CORDERO, D.R., HU, D. and HELMS, J.A. (2005). Molecular interactions coordinating the development of the forebrain and face. Dev Biol 284: 48-61.

MCGONNELL, I.M., CLARKE, J.D. and TICKLE, C. (1998). Fate map of the developing chick face: analysis of expansion of facial primordia and establishment of the primary palate. Dev Dyn 212: 102-118.

MINKOFF, R. and KUNTZ, A.J. (1977). Cell proliferation during morphogenetic change; analysis of frontonasal morphogenesis in the chick embryo employing DNA labeling indices. J Embryol Exp Morphol 40: 101-113.

MINKOFF, R. and KUNTZ, A.J. (1978). Cell proliferation and cell density of mesenchyme in the maxillary process and adjacent regions during facial development in the chick embryo. J Embryol Exp Morphol 46: 65-74.

NIMMAGADDA, S., BUCHTOVA, M., FU, K., GEETHA-LOGANATHAN, P., HOSSEINIFARAHABADI, S., TRACHTENBERG, A.J., KUO, W.P., VESELA, I. and RICHMAN, J.M. (2015). Identification and functional analysis of novel facial patterning genes in the duplicated beak chicken embryo. Dev Biol 407: 275-288.

NODEN, D.M. (1975). An analysis of migratory behavior of avian cephalic neural crest cells. Dev Biol 42: 106-130.

NODEN, D.M. (1983). The role of the neural crest in patterning of avian cranial skeletal, connective, and muscle tissues. Dev Biol 96: 144-165

NORRIS, A. and STREIT, A. (2014). Morpholinos: studying gene function in the chick. Methods 66: 454-465.

PERSON, A.D., BEIRAGHI, S., SIEBEN, C.M., HERMANSON, S., NEUMANN, A.N ., ROBU, M.E., SCHLEIFFARTH, J.R., BILLINGTON, C.J., JR., VANBOKHOVEN, H., HOOGEBOOM, J.M. et al., (2010). WNT5A mutations in patients with autosomal dominant Robinow syndrome. Dev Dyn 239: 327-337.

RICHMAN, J.M. and TICKLE, C. (1989). Epithelia are interchangeable between facial primordia of chick embryos and morphogenesis is controlled by the mesenchyme. Dev Biol 136: 201-210.

RICHMAN, J.M. and TICKLE, C. (1992). Epithelial-mesenchymal interactions in the outgrowth of limb buds and facial primordia in chick embryos. Dev Bio/154:299-308.

ROIFMAN, M., MARCELIS, C.L., PATON, T., MARSHALL, C., SILVER, R., LOHR, J.L., YNTEMA, H.G., VENSELAAR, H., KAYSERILI, H., VAN BON, B. et al., (2014). De novo WNT5A-associated autosomal dominant Robinow syndrome suggests specificity of genotype and phenotype. Clin. Genet 87:34-41

SCHNEIDER, R.A. and HELMS, J.A. (2003). The cellular and molecular origins of beak morphology. Science 299: 565-568.

SCHOCK, E.N., CHANG, C.F., STRUVE, J.N., CHANG, Y.T., CHANG, J., DELANY M.E. and BRUGMANN, S.A. (2015). Using the avian mutant talpid2 as a disease model for understanding the oral-facial phenotypes of oral-facial-digital syndrome. Dis Model Mech 8: 855-866.

SCHOCK, E.N., CHANG, C.F., YOUNGWORTH, I.A., DAVEY, M.G., DELANY, M.E. and BRUGMANN, S.A. (2016). Utilizing the chicken as an animal model for human craniofacial ciliopathies. Dev Biol 415: 326-337.

SEARLS, R.L. and JANNERS, M.Y. (1971). Initiation of Limb Bud Outgrowth in Embryonic Chick. Dev Biol 24: 198-213.

SHIGETANI, Y., NOBUSADA, Y. and KURATANI, S. (2000). Ectodermally derived FGF8 defines the maxillomandibular region in the early chick embryo: epithelialmesenchymal interactions in the specification of the craniofacial ectomesenchyme. Dev Biol 228: 73-85.

SONG, Y., HUI, J.N., FU, K.K. and RICHMAN, J.M. (2004). Control of retinoic acid synthesis and FGF expression in the nasal pit is required to pattern the craniofacial skeleton. Dev Biol 276: 313-329. 
STEPHEN, L.A., DAVIS, G.M., MCTEIR, K.E., JAMES, J., MCTEIR, L., KIERANS, M., BAIN, A. and DAVEY, M.G. (2013). Failure of centrosome migration causes a loss of motile cilia in talpid(3) mutants. Dev Dyn 242: 923-931.

STEVENTON, B., MAYOR, R. and STREIT, A. (2014). Neural crest and placode interaction during the development of the cranial sensory system. Dev Bio/389: 28-38.

SZABO-ROGERS, H.L., GEETHA-LOGANATHAN, P., NIMMAGADDA, S., FU, K.K. and RICHMAN, J.M. (2008). FGF signals from the nasal pit are necessary for normal facial morphogenesis. Dev Biol 318: 289-302.

SZABO-ROGERS, H.L., GEETHA-LOGANATHAN, P., WHITING, C.J., NIMMAGADDA, S., FU, K. and RICHMAN, J.M. (2009). Novel skeletogenic patterning roles for the olfactory pit. Development 136: 219-229.

TAK, H.J., PARK, T.J., PIAO, Z. and LEE, S.H. (2017). Separate development of the maxilla and mandible is controlled by regional signaling of the maxillomandibular junction during avian development. Dev Dyn 246: 28-40.

TAMARIN, A., CRAWLEY, A., LEE, J. and TICKLE, C. (1984). Analysis of upper beak defects in chicken embryos following with retinoic acid. J Embryol Exp Morphol 84: 105-123.

TICKLE, C., ALBERTS, B., WOLPERT, L. and LEE, J. (1982). Local application of retinoic acid to the limb bond mimics the action of the polarizing region. Nature 296: 564-566.

TRAINOR, P.A., ARIZA-MCNAUGHTON, L. and KRUMLAUF, R. (2002). Role of the isthmus and FGFs in resolving the paradox of neural crest plasticity and prepatterning. Science 295: 1288-1291.

TUCKER, A.S. and LUMSDEN, A. (2004). Neural crest cells provide species-specific patterning information in the developing branchial skeleton. Evol Dev 6: 32-40.

VEITCH, E., BEGBIE, J., SCHILLING, T.F., SMITH, M.M. and GRAHAM, A. (1999). Pharyngeal arch patterning in the absence of neural crest. Curr Bio/9: 1481-1484.
WEDDEN, S.E. (1987). Epithelial-mesenchymal interactions in the development of chick facial primordia and the target of retinoid action. Development 99: 341-351.

WU, P., JIANG, T.X., SHEN, J.Y., WIDELITZ, R.B. and CHUONG, C.M. (2006). Morphoregulation of avian beaks: comparative mapping of growth zone activities and morphological evolution. Dev Dyn 235: 1400-1412.

WU, P., JIANG, T.X., SUKSAWEANG, S., WIDELITZ, R.B. and CHUONG, C.M. (2004). Molecular shaping of the beak. Science 305: 1465-1466.

XU, Q., JAMNICZKY, H., HU, D., GREEN, R.M., MARCUCIO, R.S., HALLGRIMSSON, B. and MIO, W. (2015). Correlations Between the Morphology of Sonic Hedgehog Expression Domains and Embryonic Craniofacial Shape. Evol Biol 42: 379-386.

XU, Z.L., PARKER, S.B. and MINKOFF, R. (1990). Distribution of type IV collagen, laminin, and fibronectin during maxillary process formation in the chick embryo. Am J Anat 187: 232-246.

YEE, G.W. and ABBOTT, U.K. (1978). Facial development in normal and mutant chick embryos. I. Scanning electron microscopy of primary palate formation. $J$ Exp Zool 206: 307-321.

YIN, Y., BANGS, F., PATON, I.R., PRESCOTT, A., JAMES, J., DAVEY, M.G., WHITLEY, P., GENIKHOVICH, G., TECHNAU, U., BURT, D.W. et al., (2009). The Talpid3 gene (KIAA0586) encodes a centrosomal protein that is essential for primary cilia formation. Development 136: 655-664.

YOUNG, N.M., CHONG, H.J., HU, D., HALLGRIMSSON, B. and MARCUCIO, R.S. (2010). Quantitative analyses link modulation of sonic hedgehog signaling to continuous variation in facial growth and shape. Development 137: 3405-3409.

YOUNG, N.M., HU, D., LAINOFF, A.J., SMITH, F.J., DIAZ, R., TUCKER, A.S., TRAINOR, P.A., SCHNEIDER, R.A., HALLGRIMSSON, B. and MARCUCIO, R.S. (2014). Embryonic bauplans and the developmental origins of facial diversity and constraint. Development 141: 1059-1063. 


\section{Further Related Reading, published previously in the Int. J. Dev. Biol.}

Molecular signaling at the fusion stage of the mouse mandibular arch: involvement of insulin-like growth factor family Kazuya Fujita, Yuji Taya, Yoshihito Shimazu, Takaaki Aoba and Yuuichi Soeno

Int. J. Dev. Biol. (2013) 57: 399-406

https://doi.org/10.1387/ijdb.120110ys

\section{Expression of Wnts in the developing murine secondary palate}

Dennis R. Warner, Henry S. Smith, Cynthia L. Webb, Robert M. Greene and M. Michele Pisano Int. J. Dev. Biol. (2009) 53: 1105-1112

https://doi.org/10.1387/ijdb.082578dw

CBP/p300 and associated transcriptional co-activators exhibit distinct expression patterns during murine craniofacial and neural tube development

Vasker Bhattacherjee, Kristin H. Horn, Saurabh Singh, Cynthia L. Webb, M. Michele Pisano and Robert M. Greene

Int. J. Dev. Biol. (2009) 53: 1097-1104

https://doi.org/10.1387/ijdb.072489vb

The preplacodal region: an ectodermal domain with multipotential progenitors that contribute to sense organs and cranial sensory ganglia

Andrea Streit

Int. J. Dev. Biol. (2007) 51: 447-461

https://doi.org/10.1387/ijdb.072327as

Fate of cranial neural crest cells during craniofacial development in endothelin-A receptor-deficient mice

Makoto Abe, Louis-Bruno Ruest and David E. Clouthier

Int. J. Dev. Biol. (2007) 51: 97-105

https://doi.org/10.1387/ijdb.062237ma

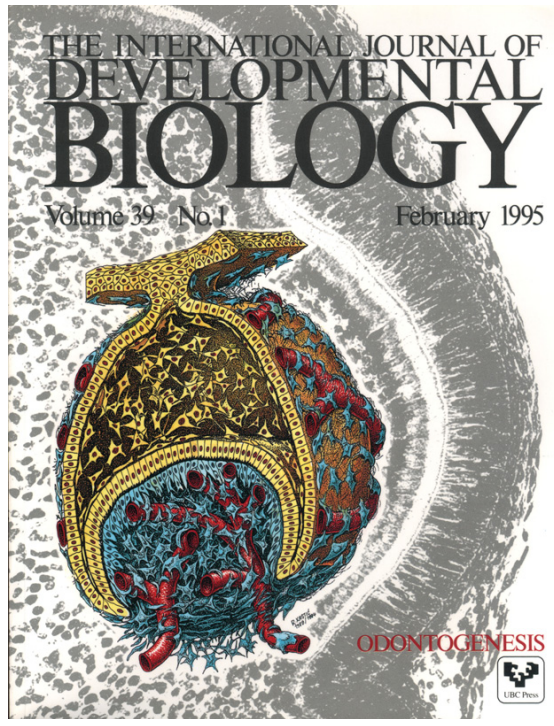

5 yr ISI Impact Factor $(2016)=2.421$
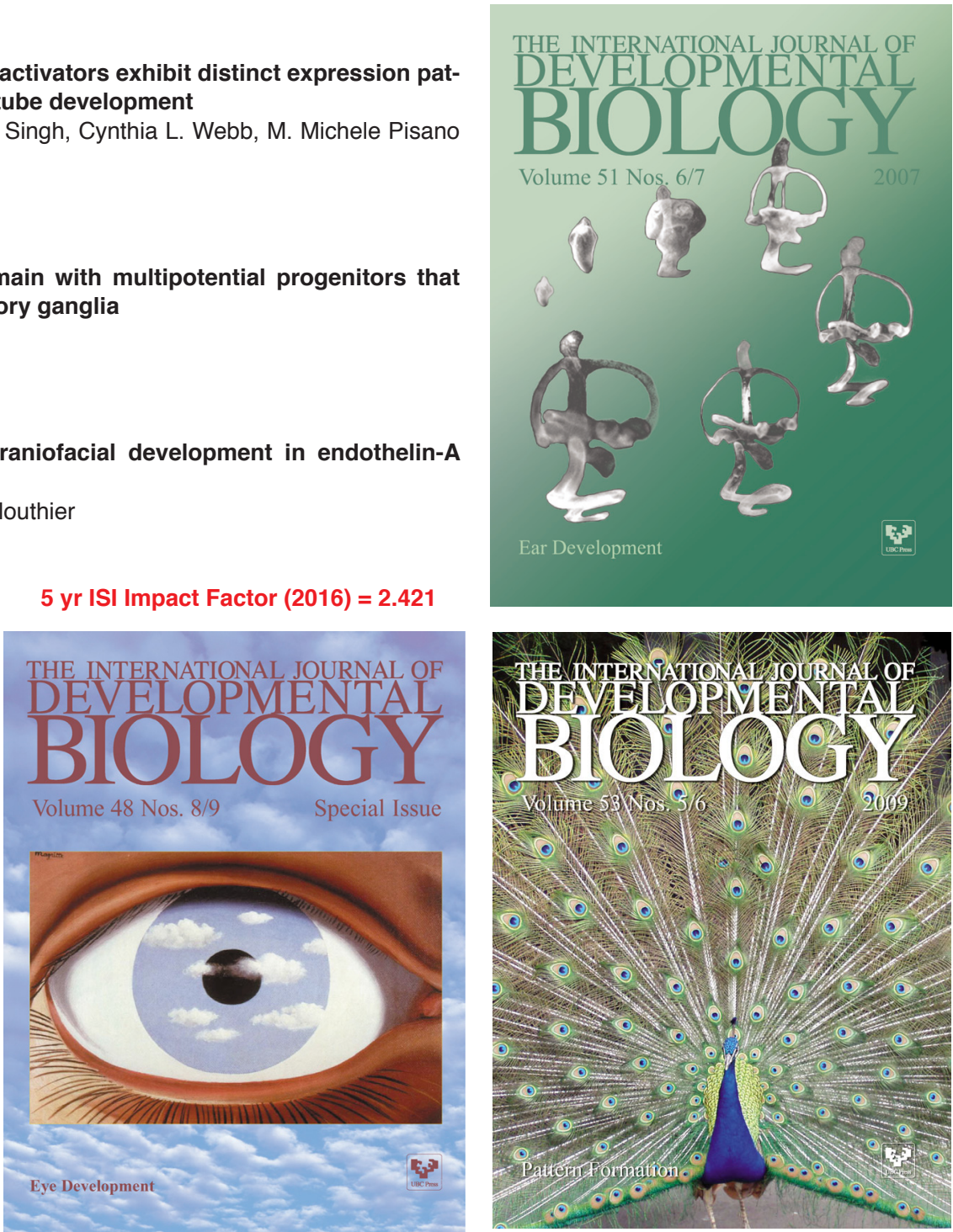